\title{
Severe Malaria in Neonates Masquerading as Septicaemia
}

\author{
Ojukwu JU*, Ezeonu CT ${ }^{* *}$, Ogbu CN***
}

\section{Summary}

\begin{abstract}
Ojukwu JU, Ezeonu CT, Ogbu CN. Severe Malaria in Neonates Masquerading as Septicaemia. Nigerian Journal of Paediatrics 2004;31:48.

Background: Malaria was once thought to be rare in the neonatal period, especially in neonates of semi-immune mothers in holoendemic areas. As a result, ill neonates admitted to newborn special care units are often presumed to have neonatal sepsis. Consequently, blood films for malaria parasites are not routinely included in the sepsis screening protocol for such neonates.

Objective: To highlight the manifestations of, and the significant morbidity associated with malaria in the newborn.

Patients and Methods: In a prospective study, all consecutive term neonates admitted for presumed sepsis during a five-month rainy season period (April to August 2002) to the Ebonyi State University Teaching Hospital, Abakaliki period were investigated for septicaemia and malaria. Septicaemia was diagnosed by positive blood culture, while malaria parasitaemia was diagnosed on Giemusa stained blood smears.
\end{abstract}

Results: Eighty four neonates were screened for sepsis and malaria parasitaemia during the study period. Out of this number, 28 (33.3 percent) had positive blood smears for malaria parasites alone, 10 (11.9 percent) had septicaemia alone, while four neonates ( 4.8 percent) had both malaria and septicaemia. Plasmodinn falliparitin was found in all positive blood smears. Twenty-four (75.0 percent) of the 32 neonates with positive malaria parasitaemia had congenital malaria, while the remaining eight (25 percent) most probably had acquired malaria. None of the neonates had transfusional malaria. Parasite densities were uniformly low. Infected neonates weighed 230 g less than the non-infected $(\mathrm{p}<$ 0.005 ). Babies of primiparae were infected with malaria parasite in significantly greater proportion than those of the multiparae $(\mathrm{p}<0.01)$. The presenting features in the 28 babies with neonatal malaria alone, included fever in 24 ( 85.7 percent), refusal of feeds in 23 ( 82.1 percent), respiratory distress in 19 (67.9 percent) and jaundice in 15 (53.6 percent). The features in the 10 babies with septicaemia alone, included refusal of feeds in 10 (100.0 percent), respiratory distress in 10 (100.0 percent), jaundice in 10 (100.0 percent) and fever in five (50.0 percent). Fever was significantly more prevalent in neonatal malaria than in septicaemia $(\mathrm{p}<0.05)$. Maternal weekly pyrimethamine prophylaxis appeared to be effective in preventing infection as 28 ( 35.4 percent) of the 79 neonates whose mothers had prophylaxis had parasitaemia compared with four ( 80.0 percent) of the five neonates whose mothers who did not $(\mathrm{p}<0.05)$. Good clinical response to chloroquine sulphate was recorded in 32 ( 86.5 percent) of 37 babies. Six (7.1 percent) other neonates with neither septicemia nor malaria responded to anti-malarial trial. One neonate died of malaria.

Conclusions: These data show that malaria can cause significant morbidity and even mortality in neonates, with its clinical signs being similar to that of neonatal sepsis. A high index of suspicion is therefore, required for the diagnosis which should be considered as a possibility in critically ill neonates in malarious areas, despite regular maternal anti-malarial prophylaxis with pyrimethamine. Initial workup for presumed neonatal sepsis in such areas should routinely include blood film for malaria parasites.

Key words: malaria, newborn, septicaemia

Ebonyi State University Teaching Hospital, Abakaliki

Department of Paediatrics
$*$ Lecturer 1/Consultant Paediatrician:
$*$ Registrar
$* *:$ Senior Lecturer/Consultant Paediatrician/
Neonatalogist

Correspondence: Ojukwu JU.

e-mail:<julieojk@yahoo.com

\section{Introduction}

MALARIA in the neonatal period was once thought to be rare especially in neonates of semi-immune mothers in holoendemic areas. ${ }^{1,2}$ As a result, sick neonates admitted to newborn special care units are often presumed to have neonatal sepsis. It was thought that maternal malario-static mechanisms protect the newborn from clinical malaria ${ }^{3}$ but Khan \& Talibi ${ }^{4}$ had indicated that immunity passively transferred to the 
neonate does not play a significant role in restricting the development of malaria parasites in the newborn. Neonatal malaria is now being increasingly reported especially in babies with presumed sepsis. ${ }^{5-10}$

Malaria in the first weeks of life can result from acquisition during pregnancy, at delivery, by mosquito bite or blood transfusion. Thus, neonatal malaria may be congenital, acquired or transfusional. ${ }^{11}$ Acquired malaria arises from mosquito bites, while transfusional malaria results from the transfusion of infected donor blood, a situation that was fairly common in endemic areas. However, congenital malaria usually results from transplacental transmission of parasitised erythrocytes which can occur between mother and foetus before or during birth. ${ }^{12,13}$ In holoendemic malarious areas, primigravity and maternal peripartum pyrexia have been associated with neonatal malaria in the peripartum period. Furthermore, the features of neonatal malaria are said to be similar to those of proven bacterial infection in the newborn. ${ }^{14-16}$ The failure of pyrimethamine prophylaxis during pregnancy to fully protect babies from congenital malaria has also been reported by various workers. $7,10,17$

For many years, chloroquine has been the drug of choice for the treatment of neonatal malaria. However, in recent years, resistance to chloroquine and to other anti-malarial drugs by Plasmodimm falciparmm has spread throughout 'many populations in Africa including Nigeria. ${ }^{6-8,10}$ Currently, there are, to the best of our knowledge, no published reports on malaria in neonates, including the role of identifiable maternal risk factors, or the course and signs of neonatal malaria in babies in Ebonyi State. These facts prompted the present study of neonatal malaria as seen during a five-month period at the Ebonyi State University Teaching HH Hospital, Abakaliki.

\section{Patients and Methods}

A five-month prospective study of all consecutive term neonates admitted for presumed sepsis into the neonatal unit of Ebonyi State University Teaching Hospital, Abakaliki (EBSUTH), was carried out. The neonatal unit of EBSUTH is the main referral centre serving the whole of Ebonyi State which has an estimated population of over two million. The Ebonyi River, from which people draw water for consumption and farming, creates several breeding sites for mosquitoes in the rainy and dry seasons. Hence, as in other parts of the State, malaria and guinea worm infestations are endemic, although the latter has largely. been controlled. The majority of the inhabitants are peasant farmers.

The study was carried out between April 1, 2002 and August 31,2002, a rainy season period. On admission into the unit, the baby's sex, estimated gestational age, age on admission, maternal parity, the duration of rupture of membrane, antepartum and peripartum pyrexia and maternal use of pyrimethamine prophylaxis during pregnancy and booking status were recorded. Mothers who had antenatal care at EBSUTTH or other orthodox health facilities and were routinely given prescription of pyrimethamine were grouped under booked cases. Unbooked cases were those mothers who did not have antenatal care. At EBSUTH, it was the practice to give pregnant women prescriptions for pyrimethamine; there was however, no assurance that the mothers of neonates in this study actually used the pyrimethamine. Babies born at the EBSUTH (inborn cases) or referred from outside (outborn cases) regardless of mother's booking status, were studied. 'The mode of delivery and the major clinical features in the infants were also documented.

The investigations carried out in all the babies with suspected sepsis inçuded full blood count, blood culture (for aerobes and anaerobes), lumbar puncture, with the cerebrospinal fluid (CSF) thus obtained being analysed and cultured, suprapubic aspirate of urine for microscopy and culture, as well as thin and thick blood films for malaria parasites. Thereafter, the neonates were commenced on intravenous ampicillin and gentamicin pending the results of the investigations. Preliminary culture results were received at 48 hours and the rest of the results within 24 hours. Septicaemia was defined as a blood-stream infection, confirmed by the isolation of bacteria from the blood. Thick peripheral blood films were stained with Gilemsa and examined for the presence of malaria parasites. The results read at $x 100$ oil immersion were graded as follows:

(i) Low density $(+)$, when there was one parasite per field.

(ii) medium density $(++)$, when there were 2-19 parasites per field.

(iii) high density $(+++)$, when the parasite load was e" 20 per field. ${ }^{18}$

Thin peripheral blood films were also stained with Giomsa for the identification of the specie of plasmodium when present. In this study, congeniti? malaria was defined as the presence of malaria parasite in a baby aged seven days, and younger.

Babies with positive malaria parasites were commenced on oral chloroquine sulphate (CQ) $25 \mathrm{mg} /$ $\mathrm{kg}$ over three days $(10 \mathrm{mg} / \mathrm{kg}$ on day 0 and 1 , and $5 \mathrm{mg} /$. $\mathrm{kg}$ on day 2) and their antibiotics were stopped 48 hours after negative results of blood, CSF and urine cultures were obtained. Babies with persistent fever or signs of progressive deterioration despite chloroquine therapy and negative cultures were re-screened for sepsis 
including CSF analysis and culture, suprapubic urine aspirate for microscopy and culture and a repeat blood film for malaria parasites. A baby was assumed to have progressive sepsis when the signs at presentation persisted or worsened after 48 hours of antibiotic therapy: Babies with negative cultures after re-screening but persistent malaria parasite despite $C Q$ therapy were switched over to oral quinine sulphate $30 \mathrm{mg} / \mathrm{kg} / \mathrm{day}$ in three divided doses for seven days. Babies with positive culture and positive malaria parasites were treated with both antibiotics according to sensitivity patterns and CQ initially. Finally, babies with negative culture and negative malaria parasite but who had persistent fever or signs of progressive deterioration were allowed to complete at least, seven days of antibiotic therapy and also treated empirically for malaria.

Statistical analysis of data was carried out using the chi-square $\left(x^{2}\right)$ and Student's ' $t$ ' tests where appropriate. A p value $<0.05$ was considered statistically significant.

\section{Results}

Eight-four neonates comprising 56 males and 28 females $(M: F=2: 1)$ were admitted for sepsis during the five-month period; 71 were inborns and 13 outborns. Their mean (SD) birthweight was $3.10(0.21) \mathrm{kg}$ and the mean (SD) gestational age, 39.92 (1.20) weeks. Thirtytwo (38.1 percent) of the 84, consisting of 23 males and nine females (2.6:1) had neonatal malaria (NM); 28 of the 32 had NM alone and the remaining four had both NM and septicaemia. Only Plasmodium falciparum trophozoites were observed in this study. None of the neonates had previously been transfused with blood. Fourteen (16.7 percent) babies had septicaemia; this included the four with both septicaemia and NM.

The mean birth weight of babies with positive malaria parasite was $2.99(0.3) \mathrm{kg}$ compared to a mean of 3.22
$(0.28) \mathrm{kg}$ in those without malaria; a difference of $230 \mathrm{~g}$ $(\mathrm{p}<0.005)$. Analysis of the age distribution shows that neonatal malaria occurred in all groups (Table I). The commonest age group at which the neonates were admitted was $0-3$ days (48.8 percent). The positive malaria parasite rates were much higher in the age groups, 16-19 and e"20 days, although the number infected was small. There was however, no significant difference between the ages of the babies and the positive malaria parasite rates $\left(\mathrm{x}^{2}=7.497, \mathrm{p}=0.1862\right)$. Twenty-four ( 75.0 percent) of the 32 infected neonates were aged seven days or younger, and were therefore, presumed to have congenital malaria (Table I); the remaining eight cases (25.0 percent) had acquired malaria. There was no transfusional malaria. Nineteen (59.4 percent) of the babies had malaria density of $(+)$, 11 (34.4 percent) had a density of $(++)$, while two $\{6.3$ percent) babies had $(+++)$. The distribution of malaria density among the babies was significant $\left(x^{2}=20.34\right.$, $\mathrm{df}=2, \mathrm{p}<0.0001$ ) in favour of malaria density $(+)$.

The clinical features in the neonates with malaria were compared with those in neonates without (Table II). The babies were grouped into four categories as follows: a) those with neonatal malaria alone; b) those with neonatal malaria and septicaemia; c) those with septicaemia alone, and d) those with neither neonatal malaria nor septicaemia.

\section{Malaria parasite positive babies}

There were 32 babies in this group. The number of babies with neonatal malaria alone who presented with fever, refusal of feeds, respiratory distress, jaundice, irritability, abdominal distension, diarrhoea and anaemia was three times or more greater than the number with neonatal malaria and septicaemia group with the same symptoms. These symptoms and signs often occurred

Table I

Age Distribution in Cases of Neonatal Malaria among 84 Neonates screened

\begin{tabular}{|c|c|c|c|c|}
\hline $\begin{array}{l}\text { Age Gioup } \\
(\text { decis })\end{array}$ & Number Screened & $\begin{array}{l}\text { Percentage } \\
\text { of Total }\end{array}$ & $\begin{array}{c}\text { Number with } \\
N M^{*}\end{array}$ & $\begin{array}{l}\text { Percentage } \\
\text { with NM }\end{array}$ \\
\hline $0-3$ & 41 & 48.8 & 19 & 46.3 \\
\hline $4-7$ & 23 & 27.4 & 5 & 21.7 \\
\hline $5-11$ & 10 & 11.9 & 3 & 30.0 \\
\hline $12-15$ & 6 & 7.1 & 2 & 33.3 \\
\hline $16-19$ & 2 & 2.4 & 1 & 5.0 \\
\hline$\geq 20$ & 2 & 2.4 & 2. & 100.0 \\
\hline Total & $84^{\circ}$ & 100.0 & 32 & \\
\hline
\end{tabular}

$* \mathrm{NM}=$ Neonatal malaria 
Table II

Clinical Features in Babies with and mitbout Neonatal Malaria

\begin{tabular}{|c|c|c|c|c|c|c|c|c|}
\hline \multirow[b]{2}{*}{ Features (n) } & \multicolumn{3}{|c|}{$\begin{array}{l}\text { Positive Malaria Parasite } \\
\qquad(N=32)\end{array}$} & \multirow[b]{2}{*}{ Percent } & \multicolumn{3}{|c|}{$\begin{array}{l}\text { Negative Malaria Parasite } \\
\qquad(N=52)\end{array}$} & \multirow[b]{2}{*}{ Percent } \\
\hline & $\begin{array}{l}N M \\
\text { alone }\end{array}$ & $N M+S$ & $*$ Total & & $\begin{array}{l}S \\
\text { alone }\end{array}$ & $\begin{array}{l}\text { Neitber } N M \\
\text { norS }\end{array}$ & Total & \\
\hline Fever $(40)$ & $24(85.7)$ & $4(100)$ & 28 & 87.5 & $(50)$ & $7(16.7)$ & 12 & 23.1 \\
\hline Refusal of feeds (64) & $23(82.1)$ & $2(50)$ & 25 & 78.1 & $10(100)$ & $29 \quad(69)$ & 39 & 75.0 \\
\hline Respiratory distress (40) & $19(67.9)$ & $4(100)$ & 23 & 71.9 & $10(100)$ & $7(16.7)$ & 17 & 32.7 \\
\hline Jaundice (71) & $15(53.6)$ & $4(100)$ & 19 & 59.4 & $10(100)$ & $42(100)$ & 52 & 100.0 \\
\hline Irritability (57) & $12(42.9)$ & $3(75)$ & 15 & 46.9 & $8 \quad(80)$ & $34(80.9)$ & 42 & 80.8 \\
\hline Abdominal distension (34) & $10(35.7)$ & $2(50)$ & $12^{\circ}$ & 37.5 & $7 \quad(70)$ & $15(35.7)$ & 22 & 42.3 \\
\hline Diarrhoea (39) & $7 \quad(25)$ & $1 \quad(25)$ & 8 & 25.0 & $6 .(60)$ & $25(59.5)$ & 31 & 59.6 \\
\hline Vomiting (29) & $4(14.3)$ & $2 \quad(50)$ & 6 & .18 .8 & $4 \cdot(40)$ & $19(45.2)$ & 23 & 44.2 \\
\hline Anaemia (20) & $5 \quad(17.9)$ & $1 \quad(25)$ & 6 & 18.8 & $5 \quad(50)$ & $9(21.4)$ & 14 & 26.9 \\
\hline Hepatomegaly (12) & $2(7.1)$ & $2(50)$ & 4 & 12.5 & $6 \quad(60)$ & $2 \quad(4.8)$ & 8 & 15.4 \\
\hline
\end{tabular}

$\mathrm{NM}=$ neonatal malaria, $S=$ septicaemia, $*$ Multiple features occurred in some neonates

The other numbers in parentheses represent percentages

Table III

Incidence of Neonatal Malaria in relation to Matemal Booking Status

Parameters

Booking S'tatus

Total

\begin{tabular}{ccr}
\hline Booked & Unbooked & \\
\hline 79 & 5 & 84 \\
28 & 4 & 32 \\
35.4 & 80.0 & 38.1
\end{tabular}

$x^{2}=3.959, \mathrm{df}=1, \mathrm{p}<0.05$

in combinations. Fever was the commonest mode of presentation in 28 ( 87.5 percent) babies followed by refusal of feeds in 25 (78.1 percent) and respiratory distress in 23 ( 71.9 percent). The other features are shown in Table II.

The babies with neonatal malaria alone were 28 in number. Their mean (SD) birthweight was $2.99(0.30) \mathrm{kg}$, mean (SD) temperature was $38.1(0.5){ }^{\circ} \mathrm{C}$, mean (SD) total white blood count was $9.1(1.7) \times 10^{\%} / \mathrm{L}$, mean (SD) neutrophils $56(0.4)$ percent, mean (SD) haemoglobin was $10.0(1.3) \mathrm{g} / \mathrm{dl}$, mean (SD) serum total bilirubin was 7.7 (3.8) mg percent and mean (SD) serum direct bilirubin was $1.5(0.58) \mathrm{mg}$ percent. Fever was the commonest symptom ( 85.7 percent), followed by refusal of feeds ( 82.1 percent) and respiratory distress (67.9 percent). One baby in this group died; he was a six-day old baby born to a primipara, with no antenatal care, who presented with refusal of feeds and respiratory distress two days prior to presentation, and had a temperature of $38^{\circ} \mathrm{C}$. He died within five hours of presentation and before anti-malarial drug could be administered. The results retrieved after the baby had died, showed malaria parasites of ++ , and negative cultures; the parents refused autopsy.

Four babies had both neonatal malaria and septicaemia; out of which one had progressive sepsis with meningitis. There was no death recorded in this group. The mean (SD) birth weight of babies in this group was $3.0(0.2)$ kilograms, mean $(\mathrm{SD})$ temperature was $37.9(0.4)^{\circ} \mathrm{C}$, mean (SD) total white blood count was $9.5(2.4) \times 10^{\circ} / \mathrm{L}$, mean (SD) neutrophils was 63 (0.2) percent, mean $(\mathrm{SD})$ serum total bilirubin was 12.8 


\section{JU Ojukwu, CT'Ezeonu, Ogbu CN}

Table IV

Maternal Parity and Neonatal Malaria

\begin{tabular}{ccccc}
\hline Parity & Number Examined & Percentage & Number Infected & Percentage Infected \\
\hline 0 & 22 & 26.2 & 14 & 63.6 \\
$1-4$ & 21 & 25.0 & 8 & 38.1 \\
$\geq 5$ & 41 & 48.8 & 10 & 24.4 \\
\hline Total & 84 & 100.0 & -32 & 38.1 \\
\hline $\mathrm{x}^{2}=9.351, \mathrm{df}=2, \mathrm{p}<0.01$ & &
\end{tabular}

Table V

Outcome of Treatment with Anti-malarial Drugs

\begin{tabular}{|c|c|c|c|c|c|c|c|c|}
\hline & \multicolumn{2}{|c|}{$\begin{array}{c}N M \\
\text { alone }(n=28)\end{array}$} & \multicolumn{2}{|c|}{$\begin{array}{c}N M+s \\
(n=4)\end{array}$} & \multicolumn{2}{|c|}{ 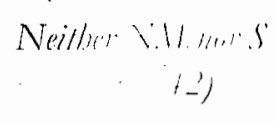 } & \multirow[b]{2}{*}{$\begin{array}{l}\text { Total No. } \\
\text { treatled }\end{array}$} & \multirow[b]{2}{*}{$\begin{array}{l}\text { Tosid No that } \\
\text { responded }\end{array}$} \\
\hline & $\begin{array}{l}\text { No. } \\
\text { treated }\end{array}$ & $\begin{array}{l}\text { No. that } \\
\text { responded }\end{array}$ & $\begin{array}{l}\text { No. } \\
\text { ireated }\end{array}$ & $\begin{array}{l}\text { No. that } \\
\text { responded }\end{array}$ & $\begin{array}{l}\text { No. } \\
\text { treated }\end{array}$ & $\begin{array}{l}\text { No. that } \\
\text { resporided }\end{array}$ & & \\
\hline Oral CQ & 27 & $22 \%$ & 4 & 4 & 6 & 6 & 37 & $32 *(86.5)$ \\
\hline
\end{tabular}

$\mathrm{NM}=$ neonatal malaria, $\mathrm{S}=$ septicaemia

* The five neonates who did not respond to chloroquine, but responded to oral quinine

was $1.7(0.65)$. Only one baby had anaemia with a haemoglobin of $8.0 \mathrm{~g} / \mathrm{dl}$; this baby also underwent exchange blood transfusion for unconjugated hyperbilirubinaemia.

\section{Malaria parasitc negative babies}

This group consisted of 52 babies. Jaundice, irritability, refusal of feeds and diarrhoea were the main presenting clinical features in this group. Jaundice was the commonest mode of presentation in 52 (100.0 percent) babies followed by irritability in 42 ( 80.8 percent) and refusal of feeds in 39 (75.0 percent). The other features

- are as shown in Table II. Fever was over three times more common in malaria parasite positive babies 87.5 percent) than in malaria parasite negative babies (23.1 percent). However, the distribution of the clinical features between the group that had neonatal malaria alone and that with septicaemia alone was not significant $\left(x^{2}=12.6, p=0.1814\right)$.

The ten babies with sicicaemia alone, had a mean (SD) birthweight of $3.11(0.26) \mathrm{kg}$, mean (SD) temperature of $38.9(0.7)$ ), mean (SD) total white blood count of $10.6(2.2) \times 10^{9} / \mathrm{L}$, mean (SD) neutrophils of 76 (1.1) percent, and a mean (SD) haemoglobin of 8.4 $(1.7) \mathrm{g} / \mathrm{dl}$, mean (SD) serum total bilirubin of $14.5(7.5)$ mg percent and mean (SD) serum direct bilirubin of 1.9 (0.5) $\mathrm{mg}$ perzent. The three major clinical features in this group were refusal of feeds (100.0 percent), respiratory distress (100.0 percent) and jaundice $(100.0$ percent). Fever was documented in five (50.0 percent) babies; it was significantly more common in the neonatal malaria group than in the septicaemic group $\left(\div^{2}=5.2\right.$, $\mathrm{p}<0.05$ ). One baby in this group had exchange blood transfusion due to elevated unconjugated hyperbilirubinaemia. Three of the babies, died; two from overwhelming septicaemia (E. colliand Staplyylococcus aureus) and the remaining one from meningitis (Enterobacter species). Two babies had urinary tract infection.

The babies with neither septicaemia nor malaria had a mean (SD) birthweight of $3.34(0.4)$ kilograms, mean (SD) temperature of $37.3^{\circ} \mathrm{C}(0.6)$, mean (SD) total white blood count of $6.7(1.8) \times 10^{\%} / \mathrm{L}$, mean $(\mathrm{SD})$ neutrophils of $40(0.6)$ percent, mean (SD) haemoglobin of $8.3(2.0)$ $\mathrm{g} / \mathrm{dl}$, mean (SD) serum total bilirubin was $17.6(6.7) \mathrm{mg}$ percent with a mean (SD) serum direct bilirubin of 1.5 (0.6) $\mathrm{mg}$ percent. All the 42 babies (100.0 percent) in this group had jaundice. Four babies underwent exchange blood transfusion for unconjugated hyperbilirubinaemia and the rest received phototherapy. 
One baby died of bilirubin encephalopathy. Twentyfive ( 86.2 percent) of the 29 babies who presented with refusal of feeds, started feeding well after 24 hours of intravenous fluid rehydration. Thirty-two (94.1 percent) of the 34 patients with irritability also improved after intravenous rehydration. Three (20.0 percent) of 15 babies with abdominal distension had intestinal obstruction and underwent surgery; one of them died from the complications of surgery.

The incidence of neonatal malaria in relation to maternal booking status is shown in Table III. Twentyeight (35.4 percent) of 79 infants of booked mothers had malaria compared to four ( 80.0 percent) of five infants of unbooked mothers, a difference that was significant $\left(\div^{2}=3.959, \mathrm{p}<0.05\right)$. All the five unbooked cases did not take pyrimethamine during pregnancy, three had peripartum pyrexia, and two had febrile illness at 32 and 36 weeks gestation, respectively. Three of the five babies were delivered at EBSUTH, two at home and one by the traditional birth attendant. There was no significant difference between the mean age of babies of booked mothers [3.5 (Q.7) days] and that of unbooked mothers $[3.9(0.6)$ days; $p>0.05]$. Analysis of the occurrence of malaria in the neonates in relation to the parity of the mother showed that the rate of malaria parasitaemia was significantly higher in the babies from primigravid mothers [Table IV; $\div^{2}=9.351, \mathrm{p}<0.01$ ]; the incidence decreased with parity.

The outcome of therapy is shown in Table V. Thirtyone ( 96.9 percent) of the 32 cases with neonatal malaria received oral CQ; 26 babies ( 83.9 percent) of these babies had a good clinical response. The remaining five cases (16.1 percent) who failed to respond to oral CQ, responded favourably to oral quinine. One (3.2 percent) baby died before he could receive CQ. All the four babies with both neonatal malaria and septicaemia responded well to oral CQ in addition to antibiotic therapy. Six babies who had neither malaria nor septicaemia but who persistently refused to feed and were irritable despite empiric antibiotic therapy for seven days received oral CQ with good clinical response. Thus, a total of 32 cases out of the 37 treated with CQ had good clinical response, resulting in a $C Q$ treatment success rate of 86.5 percent.

Six (7.1 percent) of the 84 babies died; this includes one (3.1 percent) of the 32 babies with malaria. Conversely, three (21.4 percent) of the 14 babies with septicaemia died.

\section{Discussion}

This study confirms observations by other workers ${ }^{5}$ $8,10,19$ of the increasing incidence of neonatal malaria among infants of mothers living in Nigeria. The peak age documented in our study was similar to those in other Nigerian studies ${ }^{5 \cdot 7,19}$ and elsewhere in Alrica. ${ }^{20}$ However, the male predominance was in contrast to findings by Thomas st $^{\prime 19}$ and Afolabi et $^{\prime 2}{ }^{21}$ both from Lagos, that females predominated in their studies, while Larkin and Thuma ${ }^{20}$ from Zambia recorded no sex difference. The mean birthweight of babies with neonatal malaria was significantly lower than that of babies without. This was consistent with previous Nigerian study ${ }^{22}$ and elsewhere in Africa ${ }^{23,24}$ but differed from the study by Akindele $e t a l^{7}$ who documented that infected neonates weighed $200 \mathrm{~g}$ more than non-infected neonates, although the difference was not significant. Furthermore, neonates of primigravidae in the present study had the highest rate of malarial parasitaemia, a finding that was similar to those in other Nigerian studies, ${ }^{19,22}$ but in contrast to $\mathrm{Zambian}^{20}$ and Tanzanian studies ${ }^{2+}$ which showed no correlation between neonatal parasitaemia and the parity of the mother.

A great majority of our neonates with malaria had the congenital type; this corroborates reports from other studies. ${ }^{6,19}$ It can be inferred that the infection was mostly acquired across the placenta through the materno-fetal circulation route; the remaining positive cases could have had acquired malaria from mosquito bites as none of the babies had blood transfusion. However, some of the latter could also have had congenital malaria since this type has been described in infants up to three months of age. ${ }^{16}$

The prevalence of neonatal malaria documented in the present study was high, accounting for over one third of the neonates admitted for neonatal sepsis. This was a lot higher than the previously reported prevalence from Nigeria, ${ }^{5.7}$ Lome, ${ }^{25}$ and the United States of America. ${ }^{26}$ As a result, neonatal malaria which used to be an uncommon disease even in endemic areas now seems to be causing significant morbidity in our neonates. Of particular worry because of its high rate of fatality, is the isolation of Plasmodimm falciparmm as the only offending specie; this finding confirms the findings reported in previous studies. ${ }^{57,9,10,19-21,25}$ Also in conformity with previous studies $7,19,20,25$ is the finding that most of our neonates had relatively low parasite densities. It is known that children born to mothers living in endemic areas have a combination of nonimmunological 'malariostatic' mechanisms and some protection in the form of malaria-specific immunoglobulin $\mathrm{G}$ that wanes as the child approaches the age of four months. ${ }^{27}$ This may explain the observed low parasite densities in the present study. However, some of these parasites persist to become clinically apparent, days, weeks or even months after birth. ${ }^{4,27}$ These mechanisms may also explain the fact that the positivity rates of malaria parasites was at its highest in the age group e" 16 days in the present study, although 
there was no significant difference between the age of the babies and the positive rate for malaria parasites.

The maternal weekly pyrimethamine prophylaxis appeared to be effective in preventing infection as the incidence of neonatal malaria was significantly higher in babies whose mothers did not receive pyrimethamine prophylaxis. However, as noted in previous studies, $, 17,19$ not all the babies whose mothers were supposed to have received pyrimethamine in the present study were protected from malaria. Possible reasons for this include (a) failure to purchase pyrimethamine by the mothers who were given prescriptions, (b) even when purchiased, the medication might not have been taken regularly, and (c) there might have been development of resistance and/or tolerance. This apparent failure of protection against neonatal malaria is not surprising as this has been reported in previous studies. ${ }^{5,70,17}$ It seems therefore, that despite this, pyrimethamine usage during pregnancy tended to suppress parasitaemia and thus modify the degree of infection.

Our study showed that fever was commoner with neonatal malaria than neonatal septicaemia. However, anaemia and jaundice were relatively milder in neonatal malaria than in septicaemia alone, while total white blood count and neutrophils were lower. Jaundice, respiratory distress and refusal of feeds were commoner in neonatal septicaemia than in neonatal malaria; similarly, the total white blood count and neutrophils were higher and haemoglobin levels were lower. Despite these variations however, the clinical features of neonatal malaria were generally similar to those of neonatal septicaemia. This is consistent with various other reports in Nigeria and elsewhere in Africa. ${ }^{5,6,78,10,20,2,2}$ The fact that severe neonatal malaria is not as rare as was believed in holoendemic areas and the difficulty in distinguishing its symptoms and signs from those of neonatal septicaemia, indicate that a high index of suspicion of malaria must be maintained if its diagnosis in critically ill babies is to be prompt. The high foetal and neonatal mortality from malaria may justify a trial of anti-malarial therapy in neonates with negative cultures but persistent fever. This was carried out in the present study since negative malaria parasitaemia does not exclude malaria in an endemic area."

The majority of the neonates in the present study responded favourably to oral chloroquine sulphate; the observed chloroquine treatment failure was lower than that reported by Ibhanesebhor ${ }^{11}$ who documented 25 percent treatment failure with chloroquine sulphate. Airede ${ }^{8}$ documented a neonate with congenital malaria who had poor response to treatment with chloroquine, but responded to intravenous quinine therapy. Similarly, Olanrewaju ${ }^{10}$ reported a 23 -day old baby with malaria who deteriorated while receiving chloroquine but responded favourably to halofantrine hydrochloride. These reports are not unexpected, as chloroquine resistant Plasmodimm falciparmm malaria is becoming widespread in Nigeria. ${ }^{28,29}$

Thus, our study has shown that malaria can cause significant morbidity and even mortality in neonates with its clinical signs being very similar to that of neonatal sepsis. Therefore, a high index of suspicion should be maintained for its diagnosis. Although bacteria are the commonest causes of infective illness in the newborn worldwide, neonatal malaria infection might occur more frequently in malarious areas than was previously thought. We therefore suggest that a blood film for malaria parasite be included as part of initial work-up for neonatal sepsis. Any critically ill neonate with signs of progressive illness, despite antibiotic therapy should, in addition to sepsis screening, have blood smears examined for malaria parasites. A trial of anti-malarial therapy in a neonate with negative cultures but persistent fever may be justifiable in an endemic area.

\section{Acknowledgment}

We wish to express our profound gratitude to Dr Obinna Onwujekwe for his useful criticisms and review of this manuscript.

\section{References}

1. Bruce-Chwatt IJ. Malaria in African children and infants in southern Nigeria. Ann Trop Med Partsistol 1952; 46: 173 . 200.

2. Bruce-Chwatt IJ. Acute malaria in newborn infants. BMI 1970; 3: 283.

3. Patwari AK. Childhood malaria - a perspective. Postgrad Doctor 1985; 7:33-8.

4. Khan AQ, Tablibi SA. Epidemiological assessment of malaria transmission in an endemic area of East Pakistan and the significance of congenital immunity. Bu/l Wortd Heallh Organ 1972; 46: 783-92.

5. Ibhanesebhor SE, Okolo AA. Malaria parasitaemia in neonates with predisposing risk factors for neonatal sepsis. Report of six cases. Ann Trop Paediatr 1992; 12: 297-302.

6. Ibhanesebhor SE. Clinical characteristics of neonatal malaria.J Trop Pedialr 1995; 41:330-3.

7. Akindele JA, Sowunmi A, Abohweyere AE. Congenital malaria in a hyperendemic area: a preliminary study. $A m$ Trop Prediatr 1993; 13: 273-6.

8. Airede AI. Congenital malaria with chloroquine resistance. Ann Trop Paediat 1991; 11:267-9.

9. Sowunmi A, llesanmi AO, Akindele JA, Abohweyere AEJ, Fawole AO, Falade CO, et al. Placental falciparum 
infection and outcome of pregnancy in Nigeria mothers from an endemic area. J Obset Gynaco/ 1996; 16: 211-6.

10. Olanrewaju WI. Malaria in the neonate: report of 2 cases. |Vest AfrJ Med 1999; 18:139-40.

11. Ibhanesebhor SE. The management of neonatal malaria: A review. Niger Mod Prat 1995; 30: 32-3.

12. Mengert WF, Rights CS, Bates CR Jr, Reid AF, Wolf GR, Nabors GC. Placental transmission of erythrocytes. Im J Obsiet Gyylecol 1955; 69: 678-85.

13. Zaron DM, Lichtman HC, Hellman LM. The transmission of chromium-51 tagged maternal erythrocytes from mother to fetus. AmJ J Obster Gymeol 1986; 86: 1093.

14. Jilly $P$. Anaemia in parturient women, with special reference to malaria infection of the placenta. Ann Trop Med Parrsitol 1969; 63: 109-16.

15. Sodeinde O, Dawodu AH. Neonatal transfusion malaria: A growing clinical problem. Nig.J Pateditr 1985; 2: 5760.

16. Robert D, Hindi RO, Parvin AH, Azimi MD. Congenital malaria due to plasmodium falciparum. Pediatrics 1980; $66: 977-9$.

17. Nahlen BL, Akintunde A, Alakija T, Nguyen-Dinh P, Ogunbode O, Edungbola LD, Adetoro O, Breman JG. Lack of efficacy of pyrimethamine prophylaxis in pregnant Nigerian women. L.sucet 1989; 2: 830-4.

18. Etienne L: Identification of malaria parasites. In: M Cheesbrough, LM Prescott, eds. Manual of Basic Techniques for a Health Laboratory. Geneva: WHO, 1980: 166.

19. Thomas BN, Fagbenro-Beyioku FA, Bawa-Allah MO, Kimbi HK. Evaluation of prevalence of neonatal malaria in metropolitan Lagos, Nigeria. NigJ Med Reseembl 1998; 2: 4-6.

20. Larkin GL, Thuma PE. Congenital malaria in a hyperendemic area. Am. T Trop Med Hog 1991; 45: 587 92.
21. Afolabi BM, Sodeinde O, Audu RA. Malaria in early infancy on the Atlantic coast of Lagos, Nigeria. Nig J Med Resectrith 1997; 1: 32-6.

22. Egwunyenga OA, Ajayi JA, Popovi-Duhlinska DD, Nmorsi OP. Malaria infection of the cord and birthweights in Nigerians. Cent Afr J Med 1996; 42: 265-8.

23. Morgan HG. Placental malaria and low birthweight neonates in urban Sierra Leone. Ann Trap Med Parasitol 1994; 88: 575-80.

24. Matteelli A, Donato F, Shein A, Muchi JA, Abass AK, Mariani M, Leopardi O, Maxwell CA, Carosi G. Malaria infecion and birthweight in urban Zanzibar, Tanzania. Amn Trop Med Pararitol 1996; 90: 125-34.

25. Balaka B, Agbere AD, Bonkoungou P, Kessie K, Assimadi $\mathrm{K}$, Agbo K. Congenital malaria disease due to Plasmodium falciparum in high-infection-risł̧ newborn. Arch Pediatr 2000; 7: 243-8.

26. D'Avanzo NJ, Morris VM, Carter TR, Maillard JM, Scanlon PM, Stennies GM, et cl. Congenital malaria as a result of plasmodium malariae - North Carolina, 2000.

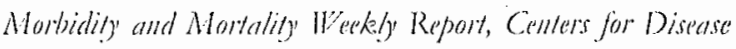
Control and Pretention 2002; 51: 164-5.

27. Sehgal VM, Siddjiqui WA, Alpers MP. A seroepidemiological study to evaluate the role of passive maternal immunity to malaria in infants. Trath R Soc Timp Med Hyg 1989; 83(suppl): 105-6.

28. Lege-Oguntoye L, A bua JU, Werblinska B, Ogalia WN, Slotboum AB, Olurinola PF. Chloroquine resistance of Plasmodium falciparum in semi-immune children in Zaria, northern Nigeria. Trans R. Soc Tiap Med Hyg 1989; 83: 599-601.

29. Ekanem OJ, Weisfeld JS, Salako LA, Nahlen BL, Ezedinach: EN, Walker O, Breman JG, Laoye OJ, Hedberg K. Sensitivity of Plasmodium falciparum to chloroquine and sulphadoxide/pyrimethamine in Nigerian children. Bull World Heallh Organ 1990; 68: 45-52. 